\title{
Local entrapment of interferon $\gamma$ in the recovery from Shigella dysenteriae type 1 infection
}

\author{
R Raqib, Å Ljungdahl, A A Lindberg, U Andersson, J Andersson
}

Laboratory Sciences

Division, International

Centre for Diarrhoeal

Diseases Research,

Bangladesh, Dhaka,

Bangladesh and

Division of Clinical

Bacteriology

R Raqib

Department of

Immunology, The

Arrhenius

Laboratories for

Natural Sciences,

Stockholm University,

Stockholm, Sweden

and Division of

Infectious Diseases

J Andersson

U Andersson

Department of Clinical

Neuroscience and

Family Medicine,

Division of Neurology

and

$\AA$ Ljungdahl

Department of

Immunology,

Microbiology,

Pathology and

Infectious Diseases,

Karolinska Institutet,

Huddinge University

Hospital, Sweden

R Raqib

Lederle Praxis

Biologicals, Wayne,

New Jersey, USA

A A Lindberg

Correspondence to:

Rubhana Raqib, Division of

Clinical Bacteriology,

Department of Immunology,

Microbiology, Pathology and

Infectious Diseases,

Karolinska Institutet,

Huddinge Hospital, S-14186

Huddinge, Sweden.

Accepted for publication

24 August 1995

\begin{abstract}
In healthy controls $(n=8)$ living in shigella endemic areas, accumulation of interferon gamma (IFN $\gamma$ ) in the epithelial lining was seen in the rectal tissues. At the single cell level, however, few or no IFN $\gamma$ protein producing cells or mRNA expressing cells were detected at that site indicating the involvement of the whole large intestine in the production of IFN $\gamma$ in controls. Persistent numbers of IFN $\gamma$ producing cells were detected in the rectum of patients with Shigella dysenteriae type 1 infection $(n=8)$ throughout the course of disease with a tendency to increase in the convalescent stage. A significantly increased extra cellular deposition of secreted IFN $\gamma$ in tissue was seen in convalescence when compared with the acute stage $(p<0.05)$. In addition, enzyme immunoassay showed increased stool concentration of IFN $\gamma$ in patients at the convalescent stage as well as in healthy controls. In situ hybridisation confirmed the results by showing increased frequency of IFN $\gamma$ mRNA containing cells at the late stage of the disease $(p<0 \cdot 05)$. Extensive message for IFN $\gamma$ was evident in cells in the lamina propria with no detectable transcripts in the surface epithelium. A colocalisation of IFN $\gamma$ with the IFN $\gamma$ receptor expression, predominantly found in the epithelial lining was detected by immunohistochemistry. Semiquantitative evaluation by computerised image analysis showed a gradual increased expression of IFN $\gamma$ and its corresponding receptor in the convalescent stage of shigellosis. This suggested progressive entrapment and binding of IFN $\gamma$ to its specific receptor at the local site. The enhanced surface expression of IFN $\gamma$ receptor evident at the convalescent stage of shigellosis was comparable to the constitutive level of expression in the healthy subjects. Thus, immunity to shigellosis correlated to up-regulation of IFN $\gamma$ production and expression of IFN $\gamma$ receptor.

(Gut 1996; 38: 328-336)
\end{abstract}

Keywords: shigellosis, IFN $\gamma$, IFN $\gamma$ receptor, pathogenesis, immune regulation.

Shigellas are Gram negative enteric bacteria that cause bacillary dysentery in humans. The pathogenic mechanisms underlying the severe inflammatory processes in shigella infection is a field of intense research. ${ }^{1-6}$ Recently, it was shown that infection with shigella was associated with increased production of proinflammatory cytokines in the rectal mucosa, which was a sustained phenomenon throughout the clinical course of the disease correlating with the persistence of inflammation. ${ }^{7}$ Immunohistochemical analysis showed a general up-regulation of all the studied cytokines, interleukin 1 alpha (IL $1 \alpha$ ), IL $1 \beta$, IL 1 receptor antagonist (IL 1 ra), IL 4, IL 6, IL 8, IL 10, tumour necrosis factor alpha (TNF $\alpha$ ), TNF $\beta$ and transforming growth factors (TGF $\beta 1-3$ ) in both acute and convalescent stages, including IFN $\gamma$ with no significant kinetic differences in the number of cytokine producing cells. The incidence of cytokine producing cells correlated to the histological severity. Stool cytokine pattern exhibited increased secretion of various cytokines reaching peak values at the acute stage of shigellosis with a sharp fall in the values during the convalescent stage. ${ }^{8} \mathrm{~A}$ discrepancy was observed for IFN $\gamma$, however, which showed different kinetics with low values at the onset of diarrhoea with a gradual continuous rise in values till the end of the study period. An important question raised by these studies was why the observed change in IFN $\gamma$ values as studied by enzyme immunoassays could not be detected by the immunohistochemical technique used. The decreased values of IFN $\gamma$ in stool might not be an effect of dilution due to increased volume of stool during the acute dysenteric phase of shigella infection. Unlike IFN $\gamma$, the rest of the studied cytokines (IL $1 \alpha$, IL 1 ra, IL 6 , IL 8, TNF $\alpha$ and granulocyte-macrophage colony stimulating factor (GM-CSF)) showed a significantly higher concentration at the acute stage with a dramatic fall at convalescence. ${ }^{8}$ Shigella derived toxins may have a selective inhibitory effect on the IFN $\gamma$ production impairing the control mechanisms of the infection.

IFN $\gamma$ is known to increase mucosal permeability by disrupting the epithelial tight junctions $^{9}$ and inducing intracellular adhesion molecules. ${ }^{10}$ This in turn enhances neutrophil transmigration across epithelial monolayers and focal break down of epithelial surface. (J H Yardley et al Proceedings of a symposium on inflammatory bowel disease, Baltimore, 1986.) In vitro studies have shown that high concentration of IFN $\gamma$ in synergy with TNF $\alpha$ may cause lysis of epithelial cells. ${ }^{11}$ In experimental tuberculosis, delayed type hypersensitivity was seen as a result of the combined effect of IFN $\gamma$, TNF $\alpha$, and IL $4 .^{12}$ High systemic doses of IFN $\gamma$ produced epithelial damage on villous tips. ${ }^{11}$ Human colonic epithelium ${ }^{13}$ and intestinal epithelial cell line $^{9}$ constitutively 
express receptors for IFN $\gamma$. We postulated that binding of IFN $\gamma$ to its receptors in the epithelial lining, irrespective of the cellular origin of IFN $\gamma$ may influence inflammatory events in shigellosis and may participate in the mucosal surface erosion and tissue destruction. Indeed it has been shown in rabbit intestinal loop model that immigration of enormous number of polymorphonuclear leucocytes at the site of infection of Shigella flexneri induced detachment of epithelial lining. ${ }^{2}$ On the other hand, IFN $\gamma$ is a major mediator of up regulation of non-specific cytocidal activity in macrophages and granulocytes by inducing formation of reactive oxygen and reactive nitrogen metabolites. ${ }^{14}$ We speculated that a selective low production of IFN $\gamma$ in the acute phase of shigella infection participates in the pathogenesis of the disease.

In this study, we examined the production and localisation of IFN $\gamma$ and TNF $\alpha$ and their corresponding receptors. In addition, localisation of the cells expressing mRNA for IFN $\gamma$ and TNF $\alpha$ in the rectal tissue during shigellosis was also studied. Enzyme immunoassays were used to measure the secreted cytokines in stool. The results suggest that (a) IFN $\gamma$ was colocalised with its specific receptor expressed on the epithelial surface as detected by immunohistochemistry; (b) there was a synchronised up-regulation of IFN $\gamma$ and the receptor from the acute phase to the convalescent stage of shigellosis; (c) using in situ hybridisation method, localisation of IFN $\gamma$ was found to be strictly in the lamina propria with no detectable transcripts in the epithelium; (d) frequency of cells containing mRNA for IFN $\gamma$ was notably higher in the convalescent stage of shigellosis.

\section{Methods}

\section{Patient population}

Adult patients (male; age range 18 to 44 years) with occult blood and mucus in stool were initially selected for the study at the study ward of the Clinical Research Centre at the International Centre for Diarrhoeal Diseases Research, Bangladesh (ICDDR,B). Routine laboratory tests were carried out for each patient, which included stool microscopy for cysts or parasites and stool culture for salmonella, shigella, and aeromonas species, Vibrio cholera and Campylobactor jejuni. Eight patients with culture confirmed Shigella dysenteriae type 1 infection were finally enrolled in the study. Written informed consent was obtained from all participants in concordance with the guidelines of the ethical review committee of the International Centre for Diarrhoeal Research, Bangladesh (ICDDR,B), Dhaka, Bangladesh. All patients received antibiotic treatment according to the sensitivity pattern (nalidixic acid and pivmecillinam). Patients underwent careful clinical investigations, which included physical examination, assessment of fever, blood pressure and pulse, stool frequency and dehydration. For clinical evaluation, blood from each patient was examined for concentrations or counts of haemoglobin, packed cell volume, total and differential leucocytes, platelets, total protein, albumin, $C$ reactive protein and creatinin; albumin and total protein content of stool was determined. Patients were released from the study ward when diarrhoea subsided (usually six to seven days). Biopsy samples from patients were collected within 48 hours of admission (two to six days after the onset of diarrhoea) and 30 days after admission (30-40 days after onset). At each time point, two biopsy specimens were obtained at proctoscopy (long-speculum Anoscope; Welch Allyn series 31610 ). These specimens were used in another study. ${ }^{7}$ Biopsy specimens were snap frozen and kept in liquid nitrogen until processed for immunohistochemistry.

On these same occasions, stool samples were also collected from each patient. ${ }^{8}$ Stool was diluted in phosphate buffered saline (pH 7.2) (1:2) containing soy trypsin inhibitor (1 $\mathrm{mg} / \mathrm{ml}$ ) and phenylsulphonyl fluoride $(1 \mathrm{mg} / \mathrm{ml})$ and centrifuged. Supernatant was collected and passed through a $0.45 \mu \mathrm{m}$ filter (Minisart N; Sartørius, Göttingen, Germany), and frozen at $-70^{\circ} \mathrm{C}$.

\section{Healthy controls}

Eight healthy adult subjects living in an endemic area were recruited as controls. Physical and clinical investigations were carried out to exclude those with a history of infection or fever within the previous five months. Informed consent was obtained from each control. Rectal biopsy specimens and stool samples were obtained from each healthy subject only once. ${ }^{78}$

\section{Immunohistochemistry}

Cryopreserved frozen tissues were sectioned at $8 \mu \mathrm{m}$ thickness and mounted on gelatin coated glass slides (SuperFrost/Plus; Menzel-Glaser, Germany). Sections were grouped into two sets and were fixed either in acetone or in paraformaldehyde. Acetone fixation entailed immersion in 50\% acetone-50\% methanol solution (Ac-Me) for two minutes at $-20^{\circ} \mathrm{C}$ followed by treatment with $100 \%$ acetone for three minutes at $-20^{\circ} \mathrm{C}$. After fixation the slides were air dried and kept in $-20^{\circ} \mathrm{C}$ until used. After rehydration in balanced salt solution (Gibco, Paisley, Scotland), endogenous peroxidase activity was quenched by incubation in freshly prepared $1 \% \mathrm{H}_{2} \mathrm{O}_{2}$ in balanced salt solution for 15 minutes. After a brief rinse in balanced salt solution, the sections were incubated for two hours in $37^{\circ} \mathrm{C}$ or overnight at room temperature with specific monoclonal antibodies at a concentration of $5 \mu \mathrm{g} / \mathrm{ml}$. Sections were incubated with normal goat serum to prevent non-specific binding followed by incubation with biotinylated goat antimouse immunoglobulin G1 (IgG1) (Caltag Laboratories, South San Francisco, CA) diluted 1:300 and biotinylated goat antirat antibody (Vector Laboratories, 
Burlingame, CA) diluted 1:100 were used as secondary antibodies for 30 minutes at room temperature. Incubation with an avidin-biotinhorseradish peroxidase complex (Vectastain, ABC-HP-kit; Vector Laboratories) at $37^{\circ} \mathrm{C}$ for 30 minutes was followed by rinsing in balanced salt solution and development with substrate chromagen (Vector Laboratories). Tissue sections were counterstained in Mayers' haematoxylin and mounted in glycerin buffer.

Fixation in paraformaldehyde entailed treatment with freshly prepared $4 \%$ paraformaldehyde in phosphate buffered saline ( $\mathrm{pH} \mathrm{7.4)}$ for 15 minutes. Sections were then rinsed in balanced salt solution and were stained as described earlier. ${ }^{7}$ The intracellular accumulation of cytokines as detected by the paraformaldehyde fixation and saponin treatment method correlates well with the cytokine production as assessed by reverse transcriptase-polymerase chain reaction (RT-PCR) technique at the mRNA level and at the protein level in culture supernatant determined by enzyme linked immunosorbent assay (ELISA) technique. ${ }^{15}$ Cytokine producing cells showing accumulation of the cytokine in the Golgi organelle may also exhibit cytoplasmic or cell surface expression of the cytokine. Absorption or endocytosis of cytokines by target cells never reveal Golgi accumulation. Addition of natural or recombinant cytokines to cultured peripheral blood mononuclear cells showed a diffuse membrane staining without the typical Golgi staining. ${ }^{16}$ Immunostaining of Ac-Me and paraformaldehyde fixed sections were run in parallel with the same antibody concentrations.

\section{Cytokine specific monoclonal antibodies}

The cytokine specific antibodies used were monoclonal mouse antihuman: IFN $\gamma$ (DIK-1, KABI-Pharmacia, Stockholm, Sweden; 7-B6, Mabtech and Genzyme Corporation, Boston, MA), TNF $\alpha$ (mAb-1 and mAb-11, PharMingen, San Diego, CA). The cytokine receptor specific antibodies used were monoclonal mouse antihuman IFN $\gamma$ receptor and TNF type I receptor (Genzyme Corporation).

Semiquantitative evaluation of immunoreactivity Quantification of immunoreactivity of the studied cytokines and the receptor was carried out by a computerised image analysing technique. ${ }^{17}$ Immunohistochemical staining of cytokines in the rectal tissue were examined with a Polyvar 2 microscope (Reichert-Jung, Vienna, Austria) equipped with a 3 CCD colour camera (Sony Corporation, Tokyo, Japan) and a Quantimet 570 image analyser (Leica Cambridge, Cambridge, UK) directed by a PC computer system. Each image was examined in Quantimet $\mathbf{5 7 0}$ for DOS (Tissue Quant 1.0) (developed by and available from Mark Litton, Department of Immunology, Stockholm University, Sweden). Standards were set for positive cells as well as for negative cells. Positive staining of a cytokine or the receptor in the cryopreserved rectal tissue was defined by computer assisted analysis of video microscopic images initially read in true colours, red, green and blue, and expressed in levels of 1-256 permitting determination of $16 \times 10^{6}$ different colours. The acquired image was divided into $512 \times 512$ pixels and each pixel was expressed in $\mu \mathrm{m}^{2}$ (area) after calibration with a magnification of $\times 200$. This technique thus permitted quantification of positive staining relative to the total area of the tissue section. The results were expressed as the percentage of the ratio of positive pixels to total pixels. The data acquired were imported to a Microsoft Excel REG dedicated macro set up (Image 2XL) (Developed by Dr T E Fehniger, Department of Immunology, Stockholm University). Details of the technique has recently been published. ${ }^{17}$

\section{In situ hybridisation}

Ten $\mu \mathrm{m}$ thick cryostat sections were fixed in $4 \%$ paraformaldehyde, washed in phosphate buffer and water respectively (one minute each step), and air dried. In situ hybridisation was performed on rectal biopsy specimens as described previously for tissues ${ }^{18}$ with ${ }^{35} S$ labelled synthetic oligonucleotide probes (Scandinivian Gene Synthesis AB, Köping, Sweden). Labelling was performed with deoxyadenosine $5^{\prime}$ - thiotriphosphate $\left({ }^{35} \mathrm{~S}\right)$ (New England Nuclear, USA) with terminal deoxynucleotidyl transferase (Amersham UK). A mixture of four different oligonucleotide probes was used to increase the sensitivity of the method. The oligonucleotide sequence was obtained from GenBank through the use of the Mac Vector system. The human IFN $\gamma$ probes (GenBank accession number J00219) ${ }^{19}$ were complementary to bases 507-556, 4682-4729, 4660-4707, and 4641-4688 and TNF $\alpha$ probes (GenBank accession number X02159, X01394) ${ }^{20}$ were complementary to bases 913-960, 22332280, 2383-2430, 2479-2526. A constant guanine/cytosine ratio of roughly $60 \%$ was used. The oligonucleotide probes were about 48 bases long and checked for the absence of long sequence homology within the species against available GenBank data. A probe complementary to the antisense strand of a human IFN $\gamma$ probe (bases 4641-4688) was used as a control probe in parallel on each section to assure the specificity of the hybridisation signals.

After in situ hybridisation, each section was examined by dark field microscopy (ReichertJung microscope, Polyvar 2; Reichert-Jung, Vienna, Austria) at $\times 100$ magnification for positive cells containing more than 30 grains per cell. Labelled cells were counted at $\times 400$ magnification. Area of each tissue section was measured by a computerised image analyser (Quantimet 570; Leica, Cambridge Ltd, Cambridge, UK). Results were expressed as number of positive cells per $1 \times 10^{5} \mu \mathrm{m}^{2}$ area of tissue section. The variability of counting procedure was $\pm 15 \%$. 
Simultaneous immunohistochemistry and in situ hybridisation for detection of IFN $\gamma$

Ficoll separated peripheral blood mononuclear cells from a healthy donor were stimulated with a superantigen staphylococcus aureus enterotoxin A to IFN $\gamma$ production. ${ }^{16}$ Cells were harvested at $24,48,72$, and 96 hours after stimulation and were fixed with $4 \%$ paraformaldehyde and stained for IFN $\gamma$ as described above. After development of colour with the substrate, slides were air dried and in situ hybridisation was performed using specific probes for IFN $\gamma$ as mentioned above.

\section{Measurement of cytokines in stool}

Concentrations of cytokines in stool from shigella infected patients and controls were measured by quantitative sandwich enzyme immunoassays. The assay systems detected both receptor bound and unbound IFN $\gamma$ (Genzyme Corporation) and TNF $\alpha$ (Medgenix Diagnostics, Fleurus, Belgium) according to the manufacturer's instruction. The minimal detectable concentrations of IFN $\gamma$ is $100 \mathrm{pg} / \mathrm{ml}$ and for TNF $\alpha$ is $3 \mathrm{pg} / \mathrm{ml}$. Interassay variation was $7-10 \%$ for repeated measurements.

\section{Data presentation}

The data were processed using Microsoft Excel 5.0 for Window (Microsoft Corporation, One Microsoft Way, Redmond, WA, USA) and JMP 3.1 (SAS Institute, Cary, NC, USA). Statistical analyses were performed using Wilcoxon/Kruskal-Wallis test and Student's $t$ test. Data are expressed as mean values and the level of significance was $\mathbf{p}<0 \cdot 05$.

\section{Results}

Tissue distribution and detection of IFN $\gamma$ producing cells at the single cell level

Paraformaldehyde fixation and saponin treatment of cryopreserved rectal tissue permitted detection of IFN $\gamma$ production at the single cell level by identifying accumulation of the cytokine to the Golgi endoplasmic reticulum (Fig 1A). Analysis using paraformaldehyde fixed tissues showed a sustained number of IFN $\gamma$ producing cells in patients with shigella infection $(n=8)$ throughout the course of disease (Table). AcMe fixation on the other hand did not permit detection of producing cells because of the disintegration of Golgi stacks caused by fixation and thus extracellular deposition of IFN $\gamma$ could only be assessed. A significant difference in the quantitative expression of IFN $\gamma$ (total area of accumulated IFN $\gamma$ in the tissue) was seen between the Ac-Me and the paraformaldehyde fixed sections from the same day specimen as quantified by automated image analysing technique (data not shown). Ac-Me fixation did not cause a non-specific staining because a complete abrogation of the signal was achieved by blocking the staining with preincubation of recombinant IFN $\gamma$ in molar excess to the anti-IFN $\gamma$ monoclonal antibody or.
anti-IFN $\gamma$ receptor antibody prior to incubation. Antibodies against IFN $\gamma$ of three different origins gave similar results. The incidence of TNF $\alpha$ producing cells in shigella infected patients in acute and convalescent stages remained unchanged (Table). However, detection of TNF $\alpha$ using two different antibodies by Ac-Me fixation could not be achieved. Receptors for TNF $\alpha$ could be localised to the epithelial lining as well as in the lamina propria cells by Ac-Me fixation.

Expression of cytokines in health controls

IFN $\gamma$ and IFN $\gamma$ receptor was seen in Ac-Me fixed tissue from healthy subjects $(n=8)$ in endemic areas predominantly in the surface epithelium and crypts (Fig 1C and D). IFN $\gamma$ and the receptor were detected both at the basal and apical sides of the epithelial cells. When compared with the quantitative expression of cytokines at the acute stage of shigella infection, a significantly increased expression $(p<0.05)$ of IFN $\gamma$ and IFN $\gamma$ receptor was exhibited in the Ac-Me fixed healthy specimens (Table). Healthy controls showed approximately twofold higher expression of IFN $\gamma$ receptor in the rectal mucosa than IFN $\gamma$. Very few or no cells producing the protein and expressing the mRNA for IFN $\gamma$ could be detected in the rectal mucosa from healthy controls. TNF $\alpha$ producing cells at this site could not be detected either in the paraformaldehyde fixed or in the Ac-Me fixed healthy tissues (Table).

\section{Mucosal surface epithelium in shigellosis do not contain $m R N A$ for IFNy}

In situ hybridisation technique was used to identify IFN $\gamma$ and TNF $\alpha$ mRNA expressing cells to verify the cytokine producing cells identified by the paraformaldehyde and saponin technique. Mostly, mRNA coding for IFN $\gamma$ and TNF $\alpha$ could be localised to cells present in the lamina propria in the rectal tissue from patients (Fig 1B). Rarely, transcripts for IFN $\gamma$ could be identified in the muscularis mucosa. No IFN $\gamma$ or TNF $\alpha$ mRNA expressing cells, however, could be detected in the epithelial lining of the mucosal surface and crypts (Fig 1B). Localisation of cells containing mRNA for IFN $\gamma$ in healthy tissues showed a similar picture as evident in patients but at much lower frequencies $(p<0.005)$. The incidence of IFN $\gamma$ mRNA expressing cells in the convalescent phase was about twofold higher than that in the acute phase of shigella infection (Table). There was no significant difference, however, in the frequency of TNF $\alpha$ mRNA expressing cells between acute and convalescent stage. In situ hybridisation technique did not show any TNF $\alpha$ mRNA expressing cells in the control biopsy specimens.

Up-regulation of IFN $\gamma$ secretion and surface expression of IFN $\gamma$ receptors in convalescence Compared with all other studied cytokines in acute stage, ${ }^{7}$ a significantly reduced IFN $\gamma$ 

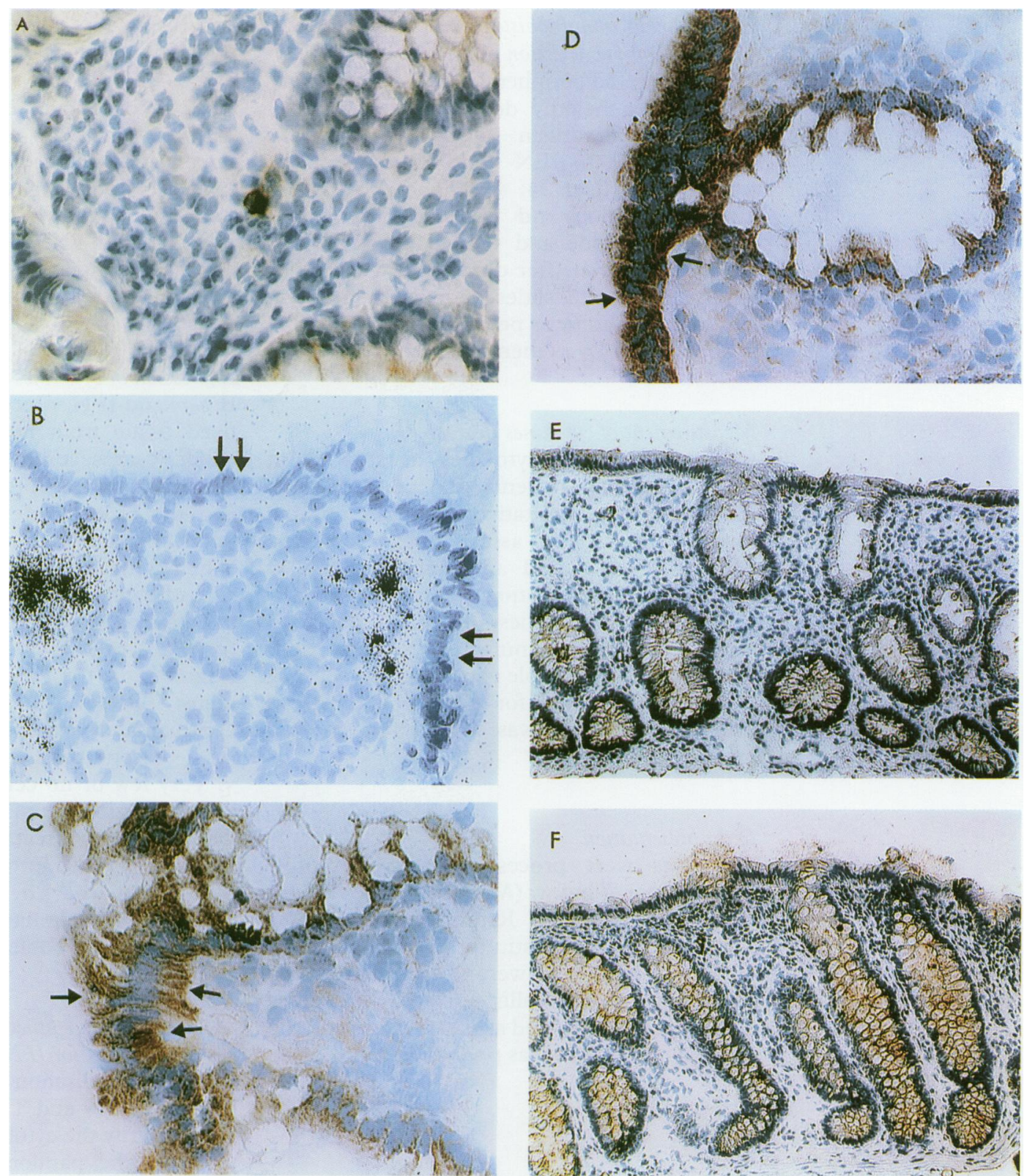

Figure 1: Colour video photographs showing localisation of IFN $\gamma$ and IFN $\gamma$ receptor in cryopreserved rectal tissues obtained from patients with shigella infection. Frozen tissue sections were stained by an immunoperoxidase method $(A, C, D, E, F)$ and counterstained with haematoxylin as described in text. Specificity of the staining was confirmed by complete abolition of the immune reactivity by preincubating cytokine specific monoclonal antibodies with the corresponding human cytokines. (A) IFN $\gamma$ producing cell in paraformaldehyde fixed rectal mucosa showing accumulation in the Golgi organelle. Original magnification $\times 200$. (B) Autoradiograph of cryostat section of a rectal biopsy specimen obtained during acute shigellosis. The section was hybridised with a ${ }^{35} S$-labelled antisense IFN $\gamma$ probe. Sections were counterstained with cresyl violet. Cells were considered to be positive if more than 30 silver grains per cell were counted. Note the expression of IFN $\gamma$ mRNA in the lamina propria only. Double arrows show absence of signal in the epithelial lining. Original magnification $\times 400$.

(C) Predominant localisation of IFN $\gamma$ receptor in the epithelial lining of mucosal surface and crypts in Ac-Me fixed tissue. Note the staining of the apical and the basal parts (arrows) of the epithelial cells for the receptor in a patient with shigella infection. Original magnification $\times 400$. (D) Identical localisation of IFN $\gamma$ in the surface epithelium (arrows) and crypts in the same patient (Ac-Me fixed tissue). Original magnification 400. (E) Reduced expression of IFN $\gamma$ in the mucosal surface and the crypts in the inflamed mucosa in acute diseased state in Ac-Me fixed tissue; note the weak staining of the surface epithelium and the crypts. Original magnification $\times 200$. (F) Increased expression of IFN $\gamma$ in the crypts and the mucosal surface in convalescence in Ac-Me fixed tissue in theame patient. Original magnification $\times 200$.

production as well as IFN $\gamma$ cell surface receptor expression was seen in Ac-Me fixed tissues during the acute phase (Fig 1E) of shigella infection (Table). Detection of cytokines at the single cell level, however, did not show any substantial difference in the number of intracellular IFN $\gamma$ and TNF $\alpha$ synthesising cells between the acute and convalescent biopsy specimens $(p<0 \cdot 7)$. Quantification of the immunostaining showed significantly decreased deposition of IFN $\gamma$ and IFN $\gamma$ receptor in Ac-Me fixed rectal tissues $(p<0.03)$ in the acute stage when compared with the convalescent stage of shigellosis (Fig 1F) (Table). In contrast with IFN $\gamma$, no difference was seen in the expression of TNF $\alpha$ and TNF $\alpha$ receptor between acute and convalescent phases (Table). Patients in the acute and convalescent stages had significantly higher number of IFN $\gamma$ producer cells in the paraformaldehyde fixed rectal tissues in comparison with healthy controls living in shigella endemic areas $(p<0.01)$. In contrast, the area of IFN $\gamma$ deposition was higher in the healthy controls than in the patients in acute stage. In addition, measurement of secreted 
Comparative analysis of IFN $\gamma$, TNF $\alpha$, and their corresponding receptors in the rectal tissues * and in stool from patients with shigellosis during acute and convalescent stages and from healthy controls

\begin{tabular}{|c|c|c|c|c|c|}
\hline & \multicolumn{5}{|c|}{ Cytokines in a total area ${ }^{*}$ and in stool extracts } \\
\hline & \multicolumn{3}{|l|}{ Patients $(n=8)$} & \multicolumn{2}{|c|}{ Controls $(n=8)$} \\
\hline & 2-6 days & 30-40 days & p Values $\$$ & & p Values \\
\hline $\begin{array}{l}\text { No of IFN } \gamma \text { producing cells } \\
\text { No of IFN } \gamma \text { mRNA expressing cells } \\
\text { Area of IFN } \gamma \text { deposition } \ddagger \\
\text { Area of IFN } \gamma \text { receptor expression } \ddagger \\
\text { Secreted IFN } \gamma \text { in stoolt } \\
\text { No of TNF } \alpha \text { producing cells } \\
\text { No of TNF } \alpha \text { mRNA expressing cells } \\
\text { Area of TNF } \alpha \text { receptor expression } \\
\text { Secreted TNF } \alpha \text { in stool }\end{array}$ & $\begin{array}{l}8 \cdot 5(2) \\
145(22) \\
16(2 \cdot 6) \\
11 \cdot 7(1 \cdot 5) \\
0 \cdot 98(0 \cdot 11) \\
10 \cdot 9(3) \\
162(21) \\
32 \cdot 4(5 \cdot 8) \\
2 \cdot 4(0 \cdot 25)\end{array}$ & $\begin{array}{l}11 \cdot 2(3) \\
315(57) \\
38 \cdot 7(4 \cdot 1) \\
33(4 \cdot 3) \\
2(0 \cdot 2) \\
9 \cdot 3(5) \\
189(19) \\
38 \cdot 1(4) \\
0 \cdot 01(0 \cdot 001)\end{array}$ & $\begin{array}{l}\text { NS } \\
0 \cdot 001 \\
0 \cdot 03 \\
0 \cdot 03 \\
0 \cdot 05 \\
\text { NS } \\
\text { NS } \\
\text { NS } \\
0 \cdot 001\end{array}$ & $\begin{array}{l}<0 \cdot 005 \\
3(1 \cdot 5) \\
25 \cdot 2(2 \cdot 8) \\
40(4 \cdot 3) \\
4 \cdot 8(0 \cdot 9) \\
0 \\
0 \\
43 \cdot 2(5) \\
0\end{array}$ & $\begin{array}{l}0 \cdot 01 \\
0.005 \\
\text { NS } \\
0 \cdot 02 \\
0 \cdot 003 \\
- \\
- \\
\text { NS } \\
-\end{array}$ \\
\hline
\end{tabular}

*Frequency of cytokine protein producing cells and cytokine mRNA expressing cells were enumerated in a tissue area of $1 \times 10^{5}$ $\mu \mathrm{m}^{2}$. + Cytokine concentrations in stool measured by commercial quantitative sandwich enzyme immunoassays were expressed in $\mu \mathrm{m}^{2}$. †. Cytokine concentrations in stool measured by commercial quantitative sandwich enzyme immunoassays were expressed in
$\mathrm{ng} / \mathrm{ml}$. One $\mathrm{ml}$ of liquid stool equalled $0.5 \mathrm{~g}$ of stool. $¥ Q$ Quantification of immunoreactive positive areas (in $\mu \mathrm{m}^{2}$ (SEM); expression $\mathrm{ng} / \mathrm{ml}$. One $\mathrm{ml}$ of liquid stool equalled $0.5 \mathrm{~g}$ of stool. $¥ Q$ Quantification of immunoreactive positive areas (in $\mu \mathrm{m}^{2}(\mathrm{SEM}) ;$ expression
of cytokines and their corresponding receptors), relative to the total section $\left(1 \times 10^{5} \mu \mathrm{m}^{2}\right)$ was examined by computer aided image of cytokines and their corresponding receptors), relative to the total section $\left(1 \times 10^{5} \mu \mathrm{m}^{2}\right)$ was examined by computer aided image
analysing technique as described in Methods. (Probability values were determined by Wilcoxon/Kruskal-Wallis test in comparing analysing technique as described in Methods. \$Probability values were determined by Wilcoxon/Kruskal-Wallis test in compa
the data between biopsy specimens obtained at $2-6$ days and 30-40 days after onset of disease and for $\{$ comparison between the data between biopsy specimens obtained at $2-6$ days
control and acute days samples. NS-not significant.

IFN $\gamma$ in stool showed significantly reduced values in acute stage in comparison with convalescence as well as with controls as seen earlier. ${ }^{8}$ Secreted TNF $\alpha$ in stool showed an opposite picture with significantly higher values in acute stage and low or undetectable values in convalescent stage (Table). TNF $\alpha$ could not be detected in stools of healthy controls.

Gradual entrapment of IFN $\gamma$ to cell surface IFN $\gamma$ receptors in the epithelial lining during recovery Consecutive sections of biopsy specimen from the same patient exhibited identical localisation of IFN $\gamma$ and IFN $\gamma$ receptor as shown by the Ac-Me fixing, predominantly in the surface epithelium and crypts (Fig 1C, D). IFN $\gamma$ could be visualised at the basal part of the epithelial cells in the surface as well as on the apical surface (Fig 1C) similar to the localisation of the receptor (Fig 1D) suggesting specific entrapment of IFN $\gamma$ to its receptors expressed in the epithelial cells as no mRNA expressing cells could be identified at this site (Fig 1B). Cells in the lamina propria and muscularis mucosa extensively expressed IFN $\gamma$ receptor albeit IFN $\gamma$ was detectable in the lamina propria to much lower extent and undetectable in the muscle layer. TNF $\alpha$ surface receptors were expressed predominantly on the surface epithelium. The intensity of the total area of TNF $\alpha$ receptor deposition was unchanged between acute and convalescent stages and was comparable to that of the healthy controls (Table).

\section{Simultaneous expression of IFN $\gamma$ protein and $m R N A$ at the single cell level}

Peripheral blood mononuclear cells stimulated with Staphylococcus aureus enterotoxin A were induced to IFN $\gamma$ production in a kinetic fashion as has been shown earlier. ${ }^{16}$ Cells stained with a characteristic perinuclear morphology (by paraformaldehyde saponin treatment) for IFN $\gamma$ were positive for mRNA detection by in situ hybridisation. A costaining pattern was established in $98 \%$ of positive cells (Fig 2). Detection of IFN $\gamma$ protein and
mRNA in the same cell (fixed with paraformaldehyde by combined immunocytochemistry and in situ hybridisation provided substantial evidence that both the techniques permitted in vitro detection of the producer cells (Fig 2) and were equally sensitive.

\section{Discussion}

Colocalisation of IFN $\gamma$ and IFN $\gamma$ receptor was evident in the epithelial lining of the mucosal surface and crypts in healthy adults as well as in patients with Shigella dysenteriae type 1 infection. Decreased secretion of IFN $\gamma$ and surface expression of IFN $\gamma$ receptor were found in the acute stage of shigella infection in contrast with all other studied cytokines. An up-regulation of IFN $\gamma$ secretion and cell surface expression of IFN $\gamma$ receptors occurred

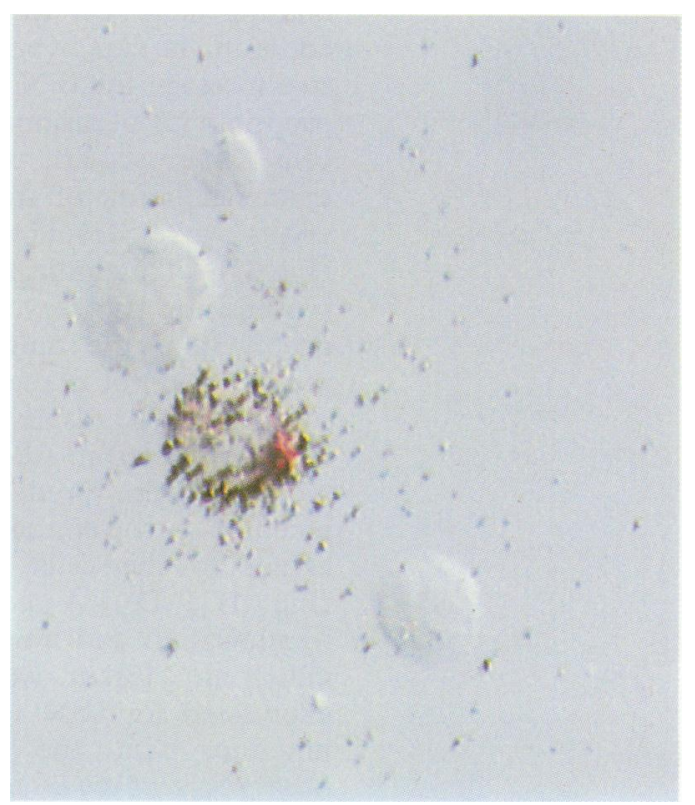

Figure 2: Combined immunohistochemistry and in situ hybridisation for the detection of IFN $\gamma$ in Staphylococcus aureus enterotoxin stimulated peripheral blood mononuclear cells allowed for the detection of both the protein and the $m R N A$ in the same cells. Note the characteristic Golgi accumulation of the cytokine (red) in the cell. Cells were harvested after 48 hours of stimulation. After paraformaldehyde fixation and saponin treatment, an alkaline phosphatase antialkaline phosphatase technique was used for the immunostaining. Magnification $\times 800$. 
conjointly, however, at the local site during the convalescent stage of the disease (Table). A significant increase in stool concentration of IFN $\gamma$ and its extra cellular deposition in tissue in the rectal mucosa was evident (Table) Concurrently, the incidence of IFN $\gamma$ mRNA expressing cells was also increased in convalescence. In our earlier study, using immunohistochemical staining of paraformaldehyde fixed rectal tissues from shigella infected patients, we concluded that the number of IFN $\gamma$ producing cells was unchanged throughout the natural course of the disease as was also evident for proinflammatory cytokines. ${ }^{7}$ Study of stool IFN $\gamma$ concentrations in the same patients by electroimmunoassay ${ }^{8}$ showed a discrepancy in the kinetic pattern when compared with the incidence of IFN $\gamma$ producing cells in rectal tissues in immunostaining. Stool and plasma concentrations of IFN $\gamma$ were low in concentration at the onset of the disease and were raised to significantly higher values at convalescence in contrast with what was seen for the other studied cytokines. ${ }^{8}$ Healthy subjects showed a selective significantly increased concentration of IFN $\gamma$ in stool. ${ }^{7}$ When compared with patients in the acute stage, healthy subjects exhibited higher deposition of IFN $\gamma$ in the surface epithelium but lower number of producer cells and mRNA expressing cells at the rectal site.. Thus IFN $\gamma$ production in healthy controls from endemic areas apparently took place not only in the rectum but also in areas remote from the rectal site.

Expression of IFN $\gamma$ surface receptors was predominantly located at the surface epithelium and crypt epithelial lining with lower expression on cells in the lamina propria (Fig 1D). Colocalisation of IFN $\gamma$ at the same site (Fig 1C) suggested accumulation and binding of IFN $\gamma$ to its specific receptor. In addition, in situ hybridisation showed extensive message for IFN $\gamma$ in cells in the lamina propria with occasional expression in isolated cells in muscularis mucosa. However, the epithelial lining of the mucosal surface and crypts were devoid of IFN $\gamma$ transcripts (Fig 1B). This indicated that cells capable of synthesising IFN $\gamma$ were located in the lamina propria and the muscle layer of the rectal mucosa and not in the epithelial lining. Taken together, these results strongly point out that IFN $\gamma$ detected in Ac-Me fixed tissue was the secreted form, predominantly bound to its receptors in the epithelial lining and to a lesser extent to the cells in the lamina propria (Fig 1C, D). A combination of in situ hybridisation and immunocytochemistry provided an elegant way of showing mRNA expression for IFN $\gamma$ in single cells in conjunction with the translated protein in Staphylococcus aureus enterotoxin A stimulated peripheral blood mononuclear cells (Fig 2). In addition, the findings showed that in an in vitro situation both in situ hybridisation and immunocytochemistry revealed the producer cells and were equally sensitive.

Both in situ hybridisation detecting IFN $\gamma$ mRNA containing cells and immunohistochemical identification (in Ac-Me-fixed tissues) of secreted protein showed significantly reduced signal in the acute stage in comparison with convalescence. Down regulation of IFN $\gamma$ and its specific receptor during acute diseased state of shigella infection in comparison with healthy controls may be due to ligand binding and internalisation of the ligand receptor complex for signalling. Nevertheless, it has been shown in in vitro studies that IFN $\gamma$ receptors are recycled after internalisation with no apparent changes in the number of cell surface receptors. ${ }^{21}$ Moreover, several studies have shown that exposure of frozen tissue sections or cultured cell lines to exogenous recombinant IFN $\gamma$ neither up regulated nor down regulated the surface receptors for IFN $\gamma \cdot{ }^{22}{ }^{23}$ Interleukin 1 has been shown to down regulate its own receptor (type I), surface expression of TNF receptors, and mRNA for IL 6 receptors. ${ }^{23}$ Bacterial antigens may also play a part in the down regulation of TNF receptors. ${ }^{24}$ Therefore, in shigellosis down regulation of IFN $\gamma$ and its receptor may be regulated by specific cytokines as well as by bacterial antigens such as shiga toxin and lipopolysaccharides. Shiga toxin is known to be processed by the Golgi complex before being routed to its 60 s ribosome target where it inhibits protein synthesis. $^{25}$ Thus, the inhibition occurs at the translational level. Shiga toxin has been shown to suppress production of lipopolysaccharide induced IL 6 and IL 8 by human umbilical vein endothelial cells. ${ }^{26}$ It is therefore plausible that shiga toxin selectively inhibits translation of IFN $\gamma$ and its receptor in the acute diseased state. It may not have a general inhibitory effect on the synthesis of other cytokines considering the fact that, increase of IL $1 \beta$, IL 6 , IL 8 , TNF $\alpha$, and GM-CSF in stool was synchronised with diminished concentrations of IFN $\gamma$ at the acute stage of the disease. ${ }^{8}$ In vitro studies have shown that IFN $\gamma$ inhibited epithelial cell invasion and intracellular multiplication by shigella species. ${ }^{27}$ Inhibition of invasiveness of shigella by IFN $\gamma$ was restricted to cells not susceptible to shiga toxin while effects of TNF $\alpha$ on invasiveness was unaffected. ${ }^{28}$ Purified shiga toxin abolished the interferon effect. Crypt epithelial cells express low levels of functional receptors for shiga toxin. ${ }^{29}$ However, shiga toxin receptors are developmentally regulated. Biosynthesis of shiga toxin receptors was enhanced by TNF treatment of human endothelial cells thereby sensitising the cells to its action. ${ }^{30}$ Thus, selective abrogation of IFN $\gamma$ at the local site in the acute stage of shigellosis may be a tactic used by the pathogen to evade the host's defence mechanisms. Lipopolysaccharides from shigellas may also play a part as endotoxins have been shown to have a regulatory role in the translation of mRNA for cytokines. ${ }^{31} 32$

Visual determination of the positive staining using a conventional microscope showed that Ac-me fixation detected the extracellular deposition of IFN $\gamma$ in the tissue (Fig 1C-F). Thus, Ac-Me fixation showed pronounced accumulation of this protein bound to its receptors in the rectal mucosa $(p<0.03)$ in the convalescent stage of shigellosis when compared with the acute stage (Table). No 
difference was established in the number of intracellular IFN $\gamma$ producing cells, however, between the acute and the convalescent biopsy specimens $(p<0 \cdot 7)$ with paraformaldehyde fixation. Thus, at the single cell level increased secretion of IFN $\gamma$ may have occurred during recovering. The up-regulation of protein kinase $\mathrm{C}$ through $\mathrm{CD} 28$-ligand interaction may stabilise mRNA resulting in an increased amount of IFN $\gamma^{33}$ due to increased neutralising antibodies to shiga toxin. ${ }^{34}$ No difference in the number of TNF $\alpha$ protein producing cells or TNF $\alpha$ mRNA expressing cells between the acute and the convalescent phases of shigellosis was obvious. These findings are compatible with and further confirm the previous reports. ${ }^{7}$ TNF $\alpha$ receptor expression was slightly lower in biopsy specimens in the acute stage in comparison with the convalescent stage or to the controls although no significant difference in the quantitative expression was achieved between these two groups.

Healthy subjects in the endemic area showed very low frequency of single cells producing IFN $\gamma$ in the rectal mucosa by paraformaldehyde fixation. However, Ac-Me fixation displayed increased extracellular entrapment. In situ hybridisation in parallel showed positively labelled cells for IFN $\gamma$ in the rectal tissues in healthy subjects though the number of positive cells were lower than in the patients. Subjects residing in a highly endemic area for shigella are presumably repeatedly exposed to the pathogen and some of them may be longterm carriers or they may have subclinical infections although stool cultures were negative for shigella. Although the rectosigmoid area is the preferential site of infection for shigellas but in the process of being exposed to the pathogen the whole large intestine is educated and there is maintenance of memory. Therefore, it is probable that cells synthesising IFN $\gamma$ are scattered throughout the intestine. The IFN $\gamma$ receptor expression in controls was roughly two times higher than the cytokine itself. Thus, these data support and extend our earlier findings that the reduced availability of the protein and mRNA for IFN $\gamma$ in acute stage of disease may be relevant to the pathogenesis of shigellosis. Thus, the combination of various techniques to detect and measure cytokines in a given disease may greatly aid in the interpretation of the findings. The delayed recovery of IFN $\gamma$ secretion and IFN $\gamma$ receptor surface expression may show that this cytokine participates in the development of immunity to the pathogen and first occurs when shigella antigens responsible for the down regulation of IFN $\gamma$ and IFN $\gamma$ receptor are neutralised by occurrence of specific antibodies to antigens.

We sincerely thank Predeep Chandra Dash for his assistance in recruiting patients and control subjects (Dhaka, Bangladesh). We are grateful to the volunteers who participated in this study (Dhaka). We gratefully acknowledge $\mathrm{H}$ Towbin (Basel) for the (Dhaka). We gratefully acknowledge $H$ Towbin (Basel) for the kind gift of antibodies. Special thanks are extended to Lars Björk and Thomas e Fehniger for providing help with the computerised image analysis technique (Stockholm, Sweden). This work was supported by grants INT-ICDDR,B-HN/03 from the countries (SAREC) and the International Centre for Diarrhoeal Diseases Research, Bangladesh (ICDDR,B), the grants awarded by the National Cancer Institute (grants nos 2490 and 2766) and the Medical Research Council (grant nos 9082 and 10850)

1 Louise CB, Obrig TG. Shiga toxin-associated haemolyticuraemic syndrome: combined cytotoxic effects of Shiga toxin, interleukin-1 $\beta$, and tumour necrosis factor alpha on human vascular endothelial cells in vitro. Infect Immun 1991; 59: 4173-9.

2 Perdomo OJ, Cavaillon JM, Huerre $M$, Ohayon $H$, Gounon P, Sansonette PJ. Acute inflammation causes epithelial invasion and mucosal destruction in experimental shigellosis. $f$ Exp Med 1994; 180: 1307-19.

3 Perdomo OJJ, Gounon P, Sansonetti PJ. Polymorphonuclear leukocyte transmigration promotes invasion of colonic epithelial monolayer by Shigella flexneri. F Clin Invest 1994; 93: 633-43.

4 Tesh VL, Ramegowda B, Samuel JE. Purified Shiga-like toxins induce expression of pro inflammatory cytokines from murine peritoneal macrophages. Infect Immun 1994; 62: 5085-94

5 Tesh VL, Samuel JE, Perera LP, Sharefkin JB, O'Brien AD. Evaluation of the role of Shiga and Shiga-like toxins in mediating direct damage to human vascular endothelial cells. F Infect Dis 1991; 164: 344-52.

6 Zychlinsky A. Fitting C, Cavaillon J-M, Sansonetti PJ. Interleukin 1 is released by murine macrophages during Interleukin 1 is released by murine macrophages during 94: 1328-32.

7 Raqib R, Lindberg AA, Wretlind B, Bardhan PK, Andersson U, Andersson J. Persistence of local cytokine production in shigellosis in acute and convalescent stages. Infect Immun 1995; 63: 289-96.

8 Raqib R, Wretlind B, Andersson J, Lindberg AA. Cytokine secretion in acute shigellosis is correlated to disease activity and detected more in stool than in plasma. $\mathcal{F}$ Infect Dis 1995; 171: 376-84.

9 Madara JL, Stafford J. Interferon- $\gamma$ directly affects barrier function of cultured intestinal epithelial monolayers. 7 Clin Invest 1989; 83: 724-7.

10 Colgan SP, Parkos CA, Delp C, Arnaout MA, Madara JL. Neutrophil migration across cultured intestinal epithelial monolayers is modulated by epithelial exposure to IFN- $\gamma$ in a highly polarised fashion. F Cell Biol 1993; 120: 785-98.

11 Sartor RB. Cytokines in intestinal inflammation: pathophysiological and clinical considerations. Gastroenterology 1994; 106: 533-9.

12 Hernandez-Pando $r$, Rook GAW. The role of TNF- $\alpha$ in $\mathrm{T}$-cell-mediated inflammation depends on the $\mathrm{Th} 1 / \mathrm{Th} 2$ cytokine balance. Immunology 1994; 82: 591-5.

13 Valente G, Ozmen L, Novelli F, Geuna M, Palestro G, Forni $G$, et al. Distribution of interferon- $\gamma$ receptor in Forni $G$, et al. Distribution of interferon- $\gamma$ recept

14 Ding AH, Nathan CF, Steuehr DJ. Release of reactive nitrogen intermediates and reactive oxygen intermediates from mouse peritoneal macrophages: comparison of activating cytokines and evidence for independent production. F Immunol 1988; 141: 2407-12.

15 Dolhain RJEM, Andersson U, Haar NT, Brinkman BMN, Verweij CL, Daha MR, et al. Detection of intracellular interferon-g by light microscopy using an immunoperoxidase technique: correlation with the corresponding mRNA and protein product. F Leukoc Biol 1993; 54: 545-51.

16 Andersson J, Nagy S, Björk L, Abrams J, Holm S, Andersson U. Bacterial toxin-induced cytokine production studied at the single-cell level Immunol Rev 1992; 127: 69-96.

17 Björk L, Andersson U, Chauvet JM, Skansén-Saphir U, Andersson J. Quantification of superantigen induced IFN- $\gamma$ production by computerised image analysis-inhibition of cytokine production and blast transformation by pooled human IgG. $\mathcal{F}$ Immunol Methods 1994; 175: 201-13.

18 Dagerlind Å, Friberg K, Bean AJ, Hökfelt T. Sensitive mRNA detection using unfixed tissue: combined radioactive and non-radioactive in situ hybridisation histochemistry. Histochemistry 1992; 98: 39-49.

19 Gray PW, Leung DW, Pennica D, Yelverton E, Najarian R, Simonsen CC, et al. Expression of human immune interferon cDNA in E coli and monkey cells. Nature 1982; 295: 503-8.

20 Pennica D, Nedwin GE, Hayflick JS, Seeburg PH, Derynck $\mathrm{R}$, Palladino MA, Kohr WJ, et al. Human tumor necrosis factor: precursor structure, expression and homology to lymphotoxin. Nature 1984; 312: 724-9.

21 Celada A, Schreiber RD. Internalization and degradation of receptor-bound interferon- $\gamma$ by murine macrophages. Demonstration of receptor recycling. F Immunol 1987; 139: 147-53.

22 Peyman JA, Hammond GL. Localization of IFN- $\gamma$ receptor in first trimester placenta to trophoblasts but lack of stimulation of HLA-DRA,-DRB, or invariant chain mRNA expression by IFN- $\gamma$. F Immunol 1994; 149: 2675-80.

23 Dinarello CA. Interleukin-1 and interleukin-1 antagonism. Blood 1991; 77: 1627-52.

24 Red H, Schlag G, Adolf GR, Natmessnig B, Davies J. Tumor necrosis factor (TNF)-dependent shedding of the p53 TNF receptor in a baboon model of bacteremia. Infect Immun 1995; 63: 297-300. 
25 Donta ST, Tomicic TK, Donohue-Rolfe A. Inhibition of Shiga-like toxins by Brefeldin A. F Infect Dis 1995; 171: $721-4$.

26 Kennedy JS, Dinarello CA. Shiga toxin inhibition of endothelial cell IL-8, IL-6 and sICAM release is dependent on pre-stimulation with LPS, TNF- $\alpha$ or IL-1 $\beta$ [Abstract]. Cytokine 1994; 6: 568.

27 Niesel DW, Hess CB, Cho YJ, Klimpel KD, Klimpel GR. Natural and recombinant interferons inhibit epithelial cell invasion by Shigella spp. Infect Immun 1986; 52: 823-33.

28 Degré $M$, Bukholm $G$, Czarniecki $C W$. In vitro treatment of $\mathrm{HEp}-2$ cells with human tumor necrosis factor- $\alpha$ and human interferons reduces invasiveness of Salmonella typhimurium. $f$ Biol Regul Homeost Agents 1989; 3: typhim $1-7$.

29 Keusch GT, Jacewicz M, Mobassaleh M, Donhue-Rolfe A Shiga toxin: intestinal cell receptors and pathophysiology of enterotoxic effects. Rev Infect Dis 1991; 13 (suppl): S304-10.

30 Van de Kar NCAJ, Monnens LAH, Karmali MA, Van Hinsbergh VWM. Tumor necrosis factor and interleukin-1 induce expression of the verocytotoxin receptor globotriaosylceramide on human endothelial cells: implication for the pathogenesis of the hemolytic uremic syndrome. Blood 1992; 80: 2755-64.

31 Kasper RL, Gehrke L. Peripheral blood mononuclear cells stimulated with $\mathrm{C} 5 \mathrm{a}$ or lipopolysaccharide to synthesise equivalent levels of IL-1 $\beta$ mRNA show unequal IL- $1 \beta$ protein accumulation but similar polyribosome profiles. f Immunol 1994; 153: 277-86.

32 Schindler R, Gelfand JA, Dinarello CA. Recombinant C5a stimulate transcription of interleukin 1 (IL-1) and tumor necrosis factor: translational signal provided by the necrosis factor: translational signal provided by the

33 Kaldy P, Schmitt-Verhulst A-M. Regulation of interferon- $\gamma$ mRNA in a cytolytic $\mathrm{T}$ cell clone: $\mathrm{Ca}^{+}$-induced transcription followed by mRNA stablization through activation of protein kinase $\mathrm{C}$ or increase in cAMP. Eur $\mathcal{F}$ Immunol 1995; 25: 889-5.

34 Islam D, Wretlind B, Ryd M, Lindberg AA, Christensson B. Immunoglobulin subclass distribution and dynamics of Shigella-specific antibody responses in serum and stool samples in shigellosis. Infect Immun 1995; 63: 2054-60. 